\title{
MULTIBACILAR LEPROSY MIMICKING SYSTEMIC LUPUS ERYTHEMATOSUS
}

Barbara Ferraço Dalmaso ${ }^{1, *}$, Ketty Lysie Libardi Lira Machado ${ }^{1}$, Laura Gonçalves Aguiar ${ }^{1}$, Heitor Filipe Surlo ${ }^{1}$, Laís Pizzol Pasti ${ }^{1}$, Paula dos Santos Athayde ${ }^{1}$, Mariana de Oliveira Macabú ${ }^{1}$, João Peçanha Schwartz ${ }^{1}$, Fernanda Sales Soares de Oliveira ${ }^{1}$, Matheus Pereira Rosi ${ }^{1}$, Luiza Lorenzoni Grillo술 Bárbara Oliveira Souza ${ }^{1}$, Tiago Barcelos da Silva ${ }^{1}$, Guilherme Vallin Garcia ${ }^{1}$, Hellen Carvalho Ribeiro ${ }^{1}$, João Victor Cornachini ${ }^{1}$, Anna Carolina Simões Moulin ${ }^{1}$, Raiza Cansian Tuão ${ }^{1}$, Débora Marques Veghini ${ }^{1}$, Gustavo Pinto de Oliveira Gomes ${ }^{1}$, Weider Andrade Tomé1, Luiza Vallory Alochio ${ }^{1}$, Luiza Correa Rodrigues Dalpiero ${ }^{1}$, Ana Paula Espindula Gianordoli ${ }^{1}$, Lídia Balarini da Silva ${ }^{1}$, Érica Vieira Serrano ${ }^{1}$, Valéria Valim ${ }^{1}$

1.Universidade Federal do Espírito Santo, Vitória (ES), Brazil.

*Corresponding author: babi_dalmaso@hotmail.com

\section{BACKGROUND}

Leprosy is an endemic disease in Brazil. Type II leprosy reactions occur in multibacillary patients, with erythema nodosum leprosum, erythema multiforme and Sweet-like, and also, fever, fatigue, headache, myalgia, involvement of peripheral nerves, lymph nodes, joints, eyes and testicles. Symptoms can often mimic autoimmune diseases (AIDs) treatment with immunosuppressants and corticosteroids can mask the diagnosis. We report the case of a patient initially treated for systemic lupus erythematosus (SLE).

\section{CASE REPORT}

A 30-year-old brown male patient, with a family history of SLE and Sjögren's syndrome, presented a flu-like illness with evening fever associated with the emergence of painful erythematous skin lesions on the back, trunk, face and upper limbs. He was diagnosed with SLE, and started hydroxychloroquine (HCQ) and prednisone. After 1 month, the lesions disappeared and he suspended treatment, losing outpatient follow-up. After 7 months, he started painful lymphadenopathy in cervical, axillary and inguinal chains, bilaterally, associated with fever of $40^{\circ} \mathrm{C}$. He sought emergency care and started dexamethasone, ceftriaxone and metronidazole, with improvement in symptoms. Subsequently, he presented recurrence of the lesions (Figure 1) with fever, arthralgia in the hands and knees and paresthesia in the upper limbs and left lower limb. After 10 days, he was transferred to a tertiary hospital, with the hypothesis of type II leprosy being raised and advised to suspend antibiotics. Autoimmune markers were requested: ANA and antiDNA were negative, RF was positive, polyclonal hyperglobulinemia, normal complements, CRP $171 \mathrm{mg} / \mathrm{dL}, \mathrm{ESR} 82 \mathrm{~mm} / 1 \mathrm{~h}$, and skin biopsy compatible with leprosy and positive bacilloscopy. The patient started treatment with clofazimine and dapsone, associated with prednisone, being discharged from the hospital after resolution of the systemic and cutaneous condition.

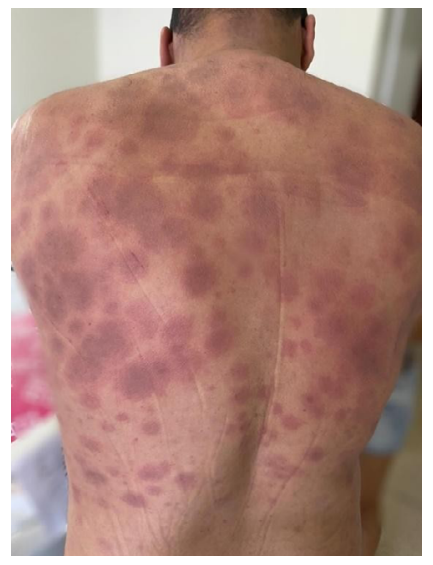

Figure 1. Circular erythematous-violaceous plaques, some with pseudovesicular borders and others with an elevated peripheral halo, compatible with type II erythema multiforme.

\section{CONCLUSION}

Multibacillary leprosy with type II reactions mimics SLE and immunosuppressive treatment can mask and delay the diagnosis. Therefore, it is important to considerer leprosy as differential diagnosis of AID such as SLE.

\section{KEYWORDS}

Leprosy, Erythema multiforme, Systemic lupus erythematosus. 